\title{
Sehari Menggugah Inspirasi Siswa Membangun Generasi Bangsa
}

\author{
Muhammad Iqbal Lintang Dalu1, Agatha Debby Reiza Macella ${ }^{2}$ \\ 1)Ikatan Alumni Universitas Diponegoro, Aceh \\ Email: lintang.sun@gmail.com \\ 2) Jurusan Ilmu Administrasi Negara, Universitas Teuku Umar \\ Email: agathadebby@utu.ac.id
}

\begin{abstract}
Children become the generation of national leaders who carry on the ideals of the nation and state. Its existence as the nation's next generation must be given the cultivation of ethical and moral values and sufficient educational provisions so that they are ready to become the next generation of national leaders. The role of parents, government and other stakeholders also plays a role in improving the quality of education. One of them is through the Inspiration Class, which is a social movement of professionals with various professions to teach one day at Elementary Schools (SD) and share stories and work experiences. The purpose of the inspirational class is to provide teaching and learning experiences, build networks, increase sensitivity to solve problems around, and provide insight, motivation, inspiration to various ideals to students and instill the value of never giving up, hard work, honesty, and independence to students. The method of this activity is socialization and interactive discussions accompanied by games to the students of the YAPSI Medan Johor Kota Medan Private Elementary School. In this activity, a description of our work is also given by playing and creating a game group so that they are interested. By using props such as posters or animation through a projector. From the observations during the activity, it can be concluded that students really need creative, fun learning methods and they need space to open their horizons and imagination regarding the world and their future.
\end{abstract}

Keywords: Inspiration Class; Ambition; Education; Generation

\begin{abstract}
Abstrak
Anak menjadi generasi pemimpin negeri yang meneruskan cita-cita bangsa dan negara. Keberadaannya sebagai generasi penerus bangsa harus diberikan penanaman nilai-nilai etika dan moral serta bekal pendidikan yang cukup sehingga mereka siap untuk menjadi generasi pemimpin bangas selanjutnya. Peran orang tua, pemerintah dan juga pemangku kepentingan lainnya turut berperan meningkatkan kualitas pendidikan. Salah satunya melalui Kelas Inspirasi yang merupakan gerakan sosial dari para profesional dengan profesi yang beragam untuk mengajar sehari ke Sekolah Dasar (SD) dan berbagi cerita serta pengalaman kerja. Tujuan kelas inspirasi yaitu memberi pengalaman belajar mengajar, membangun jejaring, meningkatkan kepekaan untuk mengatasi masalah sekitar, dan memberikan wawasan, motivasi, inspirasi beragam cita-cita kepada siswa dan menanamkan nilai pantang menyerah, kerja keras, jujur, dan mandiri kepada siswa. Metode kegiatan ini ialah sosialisasi dan diskusi interaktif disertai dengan permainan kepada siswa sekolah Dasar Swasta YAPSI Medan Johor Kota Medan. Dalam kegiatan ini juga diberikan deskripsi tentang pekerjaan kami dengan bermain dan membuat kelompok permainan agar mereka tertarik. Dengan menggunakan alat peraga seperti poster atau animasi melalui proyektor. Dari hasil pengamatan selama kegiatan dapat disimpulkan bahwa siswa sangat membutuhkan metode pembelajaran yang kreatif, menyenangkan dan mereka membutuhkan ruang untuk membuka wawasan dan imajinasi terkait dunia dan masa depan mereka.
\end{abstract}

Kata Kunci: Kelas Inspirasi; Cita-cita; Pendidikan; Generasi 


\section{PENDAHULUAN}

Anak merupakan anugerah terindah karunia yang diberikan Tuhan. Anak menjadi investasi dengan nilai yang tak terhingga bagi setiap orang tua. Berdasarkan UU No. 23 Tahun 2003 (pasal 1) tentang Perlindungan Anak bahwa anak adalah seseorang yang belum berusia 18 tahun termasuk anak yang masih di dalam kandungan. Anak adalah aset sebuah bangsa. Anak menjadi generasi pemimpin negeri yang meneruskan cita-cita bangsa dan negara. Maka sudah menjadi kewajiban sebagai orang tua untuk mempersiapkan sedari dini perihal masa depan mereka. Negara sudah berkewajiban untuk melayani dan melindungi mereka sedari lahir. Keberadaannya sebagai generasi penerus bangsa dapat dimaknai bahwasannya anakanak harus diberikan penanaman nilai-nilai etika dan moral serta bekal Pendidikan yang cukup sehingga mereka siap untuk menjadi generasi pemimpin bangas selanjutnya.

Tentunya dalam hal ini bukan hanya peran orang tua saja yang penting namun keberadaan pemerintah dan juga pemangku kepentingan lainnya ikut serta ambil bagian dengan kapasitasnya masing-masing guna mempersiapkan generasi enerus bangasa ini kelak menjadi generasi yang berakhlak, berkarakter kuat, cerdas, inovatif dan tangguh. Tujuan Pendidikan itu sendiri akan terwujud dengan adanya peran dan keterlibatan secara aktif baik dari orang tua, keluarga, guru, masyarakat, stakeholder dan lingkungan.(Nuryanto, 2019)

Seyogyanya pemerintah memberikan pelayanan bagi kemajuan generasi bangasa melalui regulasi, sistem Pendidikan, fasilitas, sarana dan prasarana pendukung lainnya untuk menunjang tumbuh kembang anak. Potensi dalam diri anak akan akan dapat berkembang dengan optimal apabila mereka berada ditengahtengah lingkungan yang positif baik secara fisik ataupun non-fisik (Irwanto et al., 2019). Pemerintah Indonesia telah berkomitmen untuk melingdungi hak-hak anak yang tertuang dalam pembukaan UUD 1945 pasal 28B ayat (2) bahwa setiap anak berhak atas kelangsungan hidup, tumbuh, dan berkembang serta berhak atas perlindungan dari kekerasan dan diskriminasi.

Berawal dari UUD 1945, perlindungan anak juga dijamin dengan adanya UU No. 23 Tahun 2002 tentang Perlindungan Anak yang semakin jelas menerangkan aspek-aspek perlindungan pada anak termasuk hak anak untuk mendapatkan informasi demi pengembangan dirinya dan hak 
untuk berkreasi sesuai dengan minat dan bakatnya. Kemudian dalam UU tersebut juga terdapat pasal mengenai kewajiban dan tanggung jawab masyarakat dalam melindungi anak melalui kegiatan peran masyarakat yang dilaksanakan dalam penyelenggaraan perlindungan anak. Hal tersebut menjadi dasar dilakukannya kelas inspirasi pada siswa sekolah dasar. Mengingat bahwa masyarakat juga berkewajiban untuk menjamin hak anak.

Membangun generasi bangsa membutuhkan waktu dan proses yang panjang. Sehingga dalam hal ni dibutuhkna kolaborasi banyak pihak untuk dapat mewujudkan generasi bangsa yang beraklak, berkarakter kuat, cerdas, inovatif dan tangguh. Kini Pendidikan karakter sudah mulai banyak ditekankan dalam kurikulum pembelajaran mulai dari Pendidikan anak usia dini hingga menengah atas namun hal ini tentunya perlu mebutuhkan dukungan dari berbagai pihak salah satunya adalah masyarakat.

Adapun bebrapa penelitian ataupun artikel ilmiah yang juga membahas mengenai keberadaan masayarakat dalam meningkatkan kualitas Pendidikan di Indonesia. Salah satunya adalah artikel berjudul Fenomena Komunikasi
Komunitas Kelas Inspirasi (Studi Fenomonologi Social Movement pada Komunitas Kelas Inspirasi pekanbaru) oleh Feby Diani Bosma (Bosma, 2017) yang lebih menitikberatkan pada motivasi anggota mengikuti kelompok kelas inspirasi dan pengalaman komunikasi yang dialami anggota. Lalu penelitian oleh Sidik Nuryanto dengan judul Partisipasi Masyarakat dalam Gerakan kelas Inspirasi yang berfokus pada partisipasi masyarakat menjadi faktor penentu kualitas pendidikan (Nuryanto, 2019) . Kemudian ada artikel yang ditulis oleh Dian Tri Wiyanti dan Tri Utami dengan judul Kelas Inspirasi-Membangun Mimpi Siswa Sekolah dasar melalui pengenalan Karakter dan Profesi (Wiyanti, Dian Tri, 2019), yang dilakukan di Semarang, di mana dalam penulisan tersebut menjelaskan bahwa kegiatan kelas inspirasi juga dilakukan di beberapa sekolah dasar di semarang dan sekitarnya melalui pengenalan karakter dan profesi .

Ramdhani Suci Lestrasi dalam penelitiannya yang berjudul Kelas insprirasi berbasis media real melalui pendekatan lesson study (Sucilestari \& Arizona, 2019) ini lebih menjelaskan mengenai metode yang digunakan saat melalukan pengajaran dalam kegiatan kelas inspirasi yang berguna bagi guru 
untuk menerapkan metode tersebut dalam proses pembelajaran sehingga dapat meningkatkan kualitas pembelajaran di kelas.

Beberapa artikel diatas semakin menguatkan bahwa ualitas Pendidikan di Indonesia perlu untuk terus menerus ditingkatkan bukan hanya dari sisi sarana dan prasarananya saja tetapi dari sisi sistem pembelajaran, metode, guru sebagai SDM nya dan juga anakanak sebagai sasasaran dari pendidikan itu sendiri. Berbagai langkah telah dilakukan oleh pemerintah untuk meningkatkan kualitas pendidikan di Indonesia, bahkan banyak pihak secara sukarela membentuk kelompok Gerakan sosial di bidang pendidikan salah satunya yaitu dengan Kelas Inspirasi.

Kelas Inspirasi merupakan gerakan sosial dari para profesional dengan latar belakang profesi yang berbeda untuk mengajar sehari ke Sekolah Dasar (SD) dan berbagi cerita serta pengalaman kerja. Selain itu juga memberikan motivasi anakanak bagaimana nantinya untuk meraih cita-cita yang mereka inginkan. Selama ini siswa hanya mendengar dari guru, televisi atau cerita orang tuanya tentang profesi yang akan menjadi cita-cita mereka di masa depan. Tetapi melalui kelas inspirasi ini cerita tersebut langsung disampaikan oleh professional di bidangnya , sehingga nantinya akan menjadi bakal inspirasi untuk para siswa bermimpi dan merangsang tumbuhnya cita-cita yang tak terbatas batas pada diri mereka (Yayasan Gerakan Indonesia Mengajar, 2015).

Terlihat pada grafik diatas bahwa mayoritas anak Indonesia berdasarkan hasil survey yang dilakukan oleh Litbang Koran Sindo tahun 2017 lalu yaitu sebesar $52 \%$ bercita-cita menjadi dokter. Padahal profesi sangat beragam bukan hanya guru, dokter, tantara, dan pilot saja bahkan petani, nelayan, pekebun juga merupakan profesi yang seharusnya dihargai dan diketahui oleh anak-anak. Apalagi di Indonesia kondisi Pendidikan masih belum merata sehingga, membutuhkna kerja keras dari semua pihak untuk memajukan genarasi bangsa, salah satu langkahnya ialah dengan membuak wawasan anak mengenai berbagai macam profesi atau pekerjaan yang nantiya dapat menjadi sumber inspirasi mereka dan bahkan menjadi keinginan mereka yang akan mereka raih ketika besar nanti.

Tujuan awal dari Kelas Inspirasi adalah menjadi awal keterlibatan para professional didalam lingkungan pendidikan disekitarnya serta Indonesia pada umumnya. Selain itu tujuan diselenggarakannya kelas inspirasi 
ada dua, yaitu memberi pengalaman belajar mengajar, membangun jejaring, meningkatkan kepekaan untuk mengatasi masalah sekitar, dan memberikan wawasan, motivasi dan inspirasi berbagai macam cita-cita kepada siswa dan juga menanamkan nilai pantang menyerah, kerja keras, jujur, dan mandiri kepada siswa (Direktorat Pembinaan dan Pendidikan Keluarga Kemdikbud, 2017).

Kelas Inspirasi bisa menjadi solusi bagi para profesional yang ingin berkontribusi dengan mengajar di sekitar tempat mereka bekerja atau di daerah lainnya. Kegiatan sosial ini juga bisa membuka pintu interaksi positif antara kaum profesional dengan dunia sekolah. Partisipasi para profesional tersebut untuk mengambil libur sehari dan berbagi pengalamannya bersama anak-anak. Kelas Inspirasi merupakan partisipasi berbasiskan individu, bukan institusi (Kelas Inspirasi, 2016). Ini menunjukkan bahwa kepedulian dan kesadaran pribadi terhadap pendidikan masih tinggi. Ke depannya, kegiatan mengajar sehari melalui Kelas Inspirasi ini diharapkan mampu mendorong kalangan profesional untuk berperan aktif dalam pendidikan melalui kegiatan serupa. "Bagi Anda hanya satu hari cuti bekerja, namun bagi murid-murid itu bisa menjadi hari yang menginspirasi mereka seumur hidup. Berbagi cerita, pengetahuan, dan pengalaman untuk menjadi cita-cita dan mimpi mereka."

\section{METODE PELAKSANAAN}

Metode yang digunakan dalam kegiatan ini ialah sosialisasi dan diskusi interaktif disertai dengan permainan kepada siswa sekolah Dasar Swasta YAPSI Medan Johor Kota Medan. Pada awal kegiatan dilakukan pembentukan panitia guna persiapan kegiatan, kemudian dilakukan survei untuk mencari lokasi dilakukannya kegiatan pengabdian ini, kemudian setelah dilakukan koordinasi tim dengan pihak sekolah YAPSI Medan Johor guna menentukan waktu dan mekanisme pelaksanaan kegiatan. Setelah itu pelaksanaan kegiatan dilakukan sesuai dengan rencana dan pembagian kelas yang sudah ditentukan sebelumnya. Dalam pelaksanaan kegiatan ini menggunakan peralatan sepetri laptop, LCD proyektor, poster, peraga dan sebagainya.

\section{HASIL DAN PEMBAHASAN}

Kegiatan kelas inspirasi ini dilaksanakan secara sukarela untuk memotivasi anak-anak usia 6-11 tahun dalam merangkai cita-cita, menambah pengetahuan mereka mengenai segala macam profesi yang nantinya dapat dijadikan cita- 
cita yang akan diraih oleh mereka ketika besar nanti.

Pada awal kegiatan mengajak beberapa orang dengan latar belakang profesi yang berbeda, kemudian berkoordinasi dengan sekolah yang akan menjadi lokasi kegiatan untuk kelas inspirasi. Kemudian pada tahapan koordinasi tersebut ada Kegiatan membangun generasi bangsan melalui kelas Inspirasi apada siswa sekolah dasar ini dilaksankan selama sehari dengan melibatkan berbagai pihak terkait bukan hanya dari sekolah sebagai tempat diselenggarakannya kelas inspirasi namun juga relawan pengajar yang terlibat di dalam kegiatan tersebut sengan berbagai profesi yang ada seperti pendongeng, technical service representative bidang farmasi peternakan, pekerja tambang, dokter, artis, penulis, pegawai BUMN (PLN), Pekerja sosial dan sebagainya. Para pengajar tersebut dibagi kedalam kelas-kelas dan diperbolehkan untuk mengemas materi yang diberikan berkaitan dengan profesinya dengan metode yang berbeda dengan kreativitasnya masing-masing. Pada kesempatan tersebut relawan pengajar juga memberikan pengetahuan mengenai profesinya, lalu menceritakan bagaimana proses bisa mencapai profesinya sehingga siswa menjadi terinspirasi untuk mencontoh dan menerapkan dalam kehidupannya serta menjadikan mereka menjadi lebih bersemangat lagi untuk belajar dan mencapai cita-cita diluar batas sesuai apa yang mereka inginkan .

Kami memberikan deskripsi tentang pekerjaan kami dengan bermain dan membuat kelompok permainan agar mereka tertarik. Dengan menggunakan alat peraga seperti poster atau animasi melalui proyektor kami menjelaskan bagaimana dunia peternakan berkembang di Indonesia. Kami juga memutar film tentang gemar berternak yang didalam video tersebut menggambarkan bagaimana dunia peternakan secara menyeluruh dalam versi anak-anak. Selain itu dalam materi juga disampaikan bagaimana caranya memerah susu sapi, bagaimana memandikan sapi, dan bagaimana memberi makan hewan ternak yang baik dan benar. Dan terakhir kami memberi semangat kepada mereka bahwa apapun yang akan mereka kerjakan kedepan itulah yang terbaik jika dilakukan dengan sungguh-sungguh.

Tentunya juga mereka diberikan bekal bahwa untuk mencapai sukses perlu berjuang dengan rajin belajar, pantang menyerah, kerja keras, jujur dan mandiri. Kelas inspirasi tersebut diikuti oleh seluruh siswa SD dari kelas 1-6 SD dan mereka sangat antusias menerima relawan pengajar yang hadir dan masuk ke dalam kelas mereka memberikan pengajaran 
sehari. Setelah proses mengajar selesai, siswa diminta untuk menuliskan cita-citanya di atas kertas berwarna-warni kemudian menempelkannnya pada pohon cita-cita yang telah disediakan oleh para relawan.

Sebagai perpisahan kami berikan cinderamata dan berfoto bersama . Pihak sekolah memberikan apresiasi pada kegiatan sosialisasi sehari ini, karena belum pernah ada sebelumnya pihak luar yang datang ke sekolah untuk memberikan motivasi dan pengetahuan kepada anak-anak terkait cita-cita dan segudang profesi yang dapat mereka tekuni ketika besar nanti.

\section{Lampiran Gambar dan Grafik}

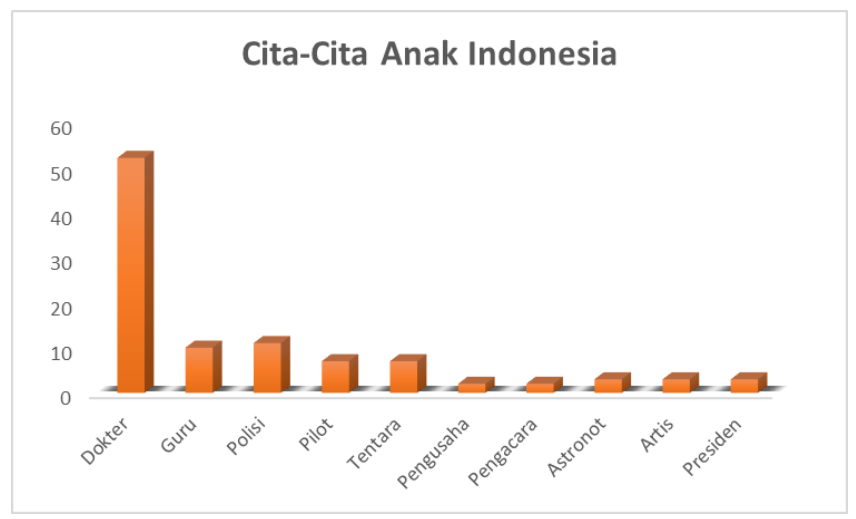

Grafik 1. Grafik Cita-Cita Anak Indonesia (Sindo, 2017)

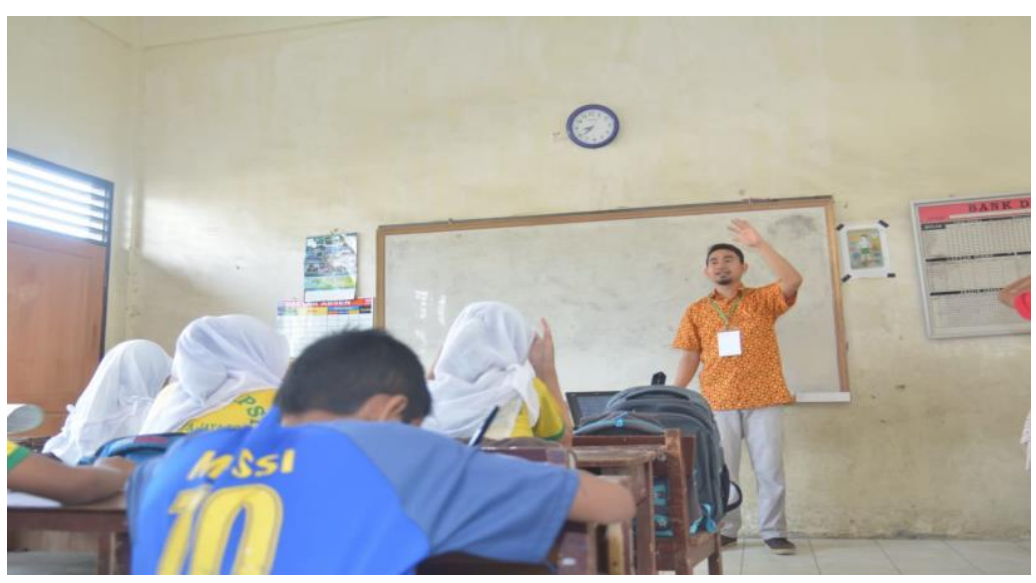

Gambar 1. Pengajaran di dalam kelas 


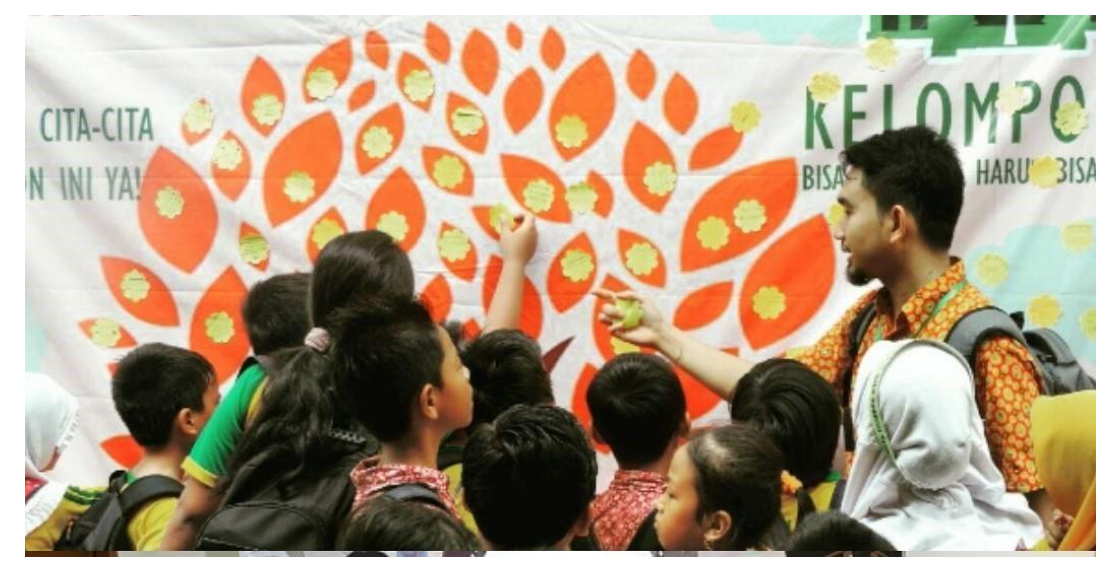

Gambar 2. Siswa menempelkan cita-citanya pada pohon cita-cita

\section{PENUTUP}

Kegiatan mengajar sehari melalui kelas inspirasi ini memberikan manfaat yang luar biasa, di mana setiap pengajar yang terlibat memiliki pengalaman tersendiri ketika harus menyampaikan materi dan pengalaman mereka yang sebelumnya belum pernah kami lakukukan. Selain itu semakin membuka wawasan dan empati kita terhadap kondisi nyata dari pendidikan di Indonesia. Kemudian para siswa sebagai sasaran kegiatan ini memberikan umpan balik yang sangat positif, di mana mereka begitu antusias mengikuti kegiatan kelas inspirasi dari awal hingga akhir.

Mereka sangat tertarik dengan materi yang disamapaikan di dalam kelas. Berdasarkan itulah dapat kami simpulkan bahwa siswa sekolah dasar sangat membutuhkan metode pembelajaran yang kreatif dan menyenangkan agar mereka tidak bosan dengan cara pembelajaran yang klasikal dan monoton. Selain itu mereka memerlukan ruang yang luas untuk membuka wawasan dan imajinasi mereka terkait dunia dan masa depan mereka, sehingga dapat mempengaruhi daya dan pola pikir mereka. Sehingga dapat meningkatkan kecerdasan dan kreatifitas anak.

Oleh sebab itulah adapun beberapa saran yang dapat dilakukan bagi orang tua, guru, sekolah, pemerintah dan masyarakat dalam memberikan sumbang sih nya untuk membangun generasi penerus bangsa yaitu:

a. Adanya dialog sehari-hari antara orang tua dan anak tentang keinginan atau minat anak sehingga orang tua dapat memfasilatasi dan mengarahkan sesuai dengan minat dan bakat anak. 
b. Pemberian pembelajaran di kelas oleh guru dengan metode yang variatif dan memberikan ruang kreatifitas pada siswa dalam proses belajar.

c. Sekolah perlu untuk melakuan kegiatan sosialisasi secara berkala dengan mengajak pihak swasta ataupun perguruan tinggi dan Lembaga sosial masyarakat yang ada di sekitar sekolah dalam meningkatkan pengetahuan siswa, meningkatkan kreativitas serta pemberian motivasi kepada anak-anak untuk selalu semangat belajar demi meraih cita-cita yang diinginkan dengan melakukan.

d. Pemerintah dan masyarakat diharapkan dapat berkolaborasi secara aktif dalam pembangunan generasi penerus bangsa melalui berbagai macam program maupun kegiatan yang dilaksnakan secara kelompok dan individu baik di tingkat pusat maupun daerah sehingga tujuan Pendidikan di Indonesia dapat lebih cepat tercapai.

\section{DAFTAR PUSTAKA}

Bosma, F. D. (2017). Fenomena komunikasi komunitas kelas inspirasi (studi fenomenologi. Jom FISIP , 4(2), 1-13. https://media.neliti.com/medi a/publications/207103fenomena-komunikasikomunitas-kelas-insp.pdf

Direktorat Pembinaan dan
Pendidikan Keluarga

Kemdikbud. (2017). Penguatan

Kelas Inspirasi. Kementrian

Pendidikan dan Kebudayaan. https:/ / sahabatkeluarga.kemdi kbud.go.id/laman/uploads/D okumen/4685_2017-0411/MATERI BIMTEK KELAS INSPIRASI.pdf

Irwanto, D., P, C. A. P., \& Hanoraga, G. B. (2019). KELAS INSPIRASI UNTUK MENUMBUHKAN MOTIVASI SISWA SDN 1 JUKONG. Jurnal Abdikarya, 03(1), 82-84.

Kelas Inspirasi. (2016). Kelas

Inspirasi.

http:/ / kelasinspirasi.org/index Nuryanto, S. (2019). Partisipasi

Masyarakat dalam Gerakan

Kelas. Southeast Asian Journal of Islamic Education, 02, 111-126.

Sindo. (2017). 10 Cita-Cita Idaman Anak Indonesia, Dokter Paling Diminati. Sindonews.Com. https:/ / lifestyle.sindonews.co $\mathrm{m} /$ berita/1263701/166/10-citacita-idaman-anak-indonesiadokter-paling-diminati

Sucilestari, R., \& Arizona, K. (2019). KELAS INSPIRASI BERBASIS MEDIA REAL MELALUI PENDEKATAN Pendahuluan Perguruan tinggi sebagai pengemban amanah dalam menjawab tantangan zaman. Jurnal Pengabdian Masyarakat, 15(1), 23-34.

https://journal.uinmataram.ac. id/index.php/transformasi/art icle/view/964/635

Wiyanti, Dian Tri, T. U. K. (2019).

Kelas Inspirasi - Membangun Mimpi Siswa Sekolah Dasar 
melalui Pengenalan Karakter

dan Profesi. Jurnal Abdimas,

23(1), 64-67.

https://journal.unnes.ac.id/nju

/index.php/abdimas/article/v

iew/17602/8894

Yayasan Gerakan Indonesia

Mengajar. (2015). Panduan kelas

inspirasi. Yayasan Gerakan

Indonesia Mengajar.

Undang-Undang Nomor 23 Tahun

2002 Tentang Perlindungan Anak 